\title{
The Birth of the Obesity Clinic: Confessions of the Flesh, Biopedagogies and Physical Culture
}

\author{
Geneviève Rail \\ Concordia University
}

The recent construction of a so-called "obesity epidemic" has been fueled by epidemiologically-based studies recuperated by the media and suggestions of the rapid acceleration of obesity rates in the Western world. Studies linking obesity to ill-health have also exploded and greatly impacted our "physical" culture. In this article, I present a series of postcards to summarize the dominant obesity discourse and document the rhetorical terrain of the impending epidemic. I also offer counter-postcards to dispute the postcards' objective postulations and contextualize the birth of what I call the "Obesity Clinic." I then characterize this polymorphous clinic as an apparatus of capture sustained by biomedicalization, bioeconomics, and biocultural discourses and speak to its regulation and abjection of unruly (fat) bodies. I conclude with a few reflections about the territorializing nature of the Obesity Clinic as well as what it means for individuals and, more generally, for physical culture and its study.

La construction récente d'une soi-disant "épidémie d'obésité » a été alimentée par des études épidémiologiques récupérées par les médias et la suggestion d'une accélération rapide des taux d'obésité dans le monde occidental. Les études liant l'obésité à la mauvaise santé ont aussi explosé et grandement influencé notre culture «physique ». Dans cet article, je présente une série de cartes postales pour résumer le discours dominant sur l'obésité et documenter le terrain rhétorique propre à l'épidémie imminente. Je propose également des contre cartes postales afin de contester les postulats objectifs des cartes postales et de mettre en contexte la naissance de ce que j'appelle la «Clinique de l'obésité ». Je parle de cette clinique polymorphe en tant qu'appareil de capture soutenu par la biomédicalisation, le bioéconomique et les discours bioculturels. Je parle également de sa réglementation et de son abjection des corps gros et indisciplinés. Je conclus par quelques réflexions sur la Clinique de l'obésité et sa façon de territorialiser ainsi que ce que cela signifie pour les individus et, plus généralement, pour la culture physique et son étude.

Sport and bodily practices that make up our physical culture are not neutral. Throughout the times, they have been instrumental to the success of various

Rail is with the Simone de Beauvoir Institute, Concordia University, Montreal, Quebec, Canada. 
biopolitical projects. In recent years, they have been reconceptualized as crucial weapons in the "war on obesity" (Rail, Holmes \& Murray, 2010, p. 259). This reconfiguration of physical culture has taken place concomitantly with the dramatic increase of epidemiological, physiological, and medical literature on obesity (see overviews in Gard, 2011; Gard \& Wright, 2005) and its recuperation by the media, educational institutions, health and fitness practitioners, and public health officials. The "crisis" is said to afflict an increasing number of countries in the world where physical activity and dietary restraint are lacking. According to the World Health Organization (WHO), it threatens a global health catastrophe. The WHO has thus declared obesity a "serious disease" $(2000$, p. 4) and recommended methods to limit the "global obesity epidemic" (2011, np).

While biomedicine occupies the "normative position" (Wright, 2009, p. 5) when it comes to the issue of obesity, obesity research has recently widened to include provocative new studies by social scientists and a few biomedical researchers who have challenged the use of the term "epidemic" (Campos et al., 2006; Gard, 2004), the notion of obesity as a disease (Gaesser, 2003a; Oliver, 2006; Ross, 2005), the burden of disease due to obesity (Gaesser, 2003b, 2003c; Mark, 2005), the attribution of deaths to obesity (Farrell, Braun, Barlow, Cheng, \& Blair, 2002; Flegal, Graubard, Williamson, \& Gail, 2005; Mark, 2005), and the identification of obesity as a public health priority (Campos et al., 2006; Evans \& Colls, 2009; LeBesco, 2010). These authors and others have also noted contradictions regarding obesity's measurement, causes, solutions, and interventions (Gaesser, 2009; Herrick, 2007; Holm, 2007; Komesaroff \& Thomas, 2007; Rich, Monaghan \& Aphramor, 2011). These critical debates have raised highly significant questions but, unfortunately, they have mostly taken place away from the public.

Meanwhile, popular media stories feeding fear and anxiety over obesity have continued to flourish (Boero, 2007; Gard, 2009; Saguy \& Almeling, 2008). Weight loss reality shows have appeared on television screens in many countries such as the United States (e.g., Big Medicine, The Biggest Loser, Biggest Loser Club, Celebrity Fit Club, Dance Your Ass Off, Jamie Oliver's Food Revolution; Obesity: The Series, Weighin In), Australia (e.g., The Biggest Loser-Australia, Biggest Loser ClubAustralia, Overhaul, Celebrity Overhaul), Canada (e.g., Taking It Off, X-Weighted, The Last 10 Pounds Bootcamp, Village on a Diet), and the United Kingdom (e.g., Honey We're Killing The Kids, Supersize vs Superskinny, You Are What You Eat). In fact, researchers have documented the explosion of obesity-related stories and programs in Canada (Holmes, 2009), the United States (Campos, 2004; Oliver, 2005; Orbach, 2006; Saguy \& Almeling, 2008; Saguy \& Gruys, 2010), Australia (Gard \& Wright, 2005; Gard, 2011), and England (Evans, Rich, Davies \& Allwood, 2008; Evans, Rich, Allwood, \& Davies, 2005; Evans, Rich \& Davies, 2004). The above authors have invariably recognized the presence of a dominant "obesity discourse." This discourse offers a mechanistic view of the body that emphasizes an assumed relationship between inactivity, poor diet, obesity, and poor health. Concurrently, obesity is presented in moral and economic terms and this is where it is at its most problematic: obese and "at-risk" (i.e., overweight) bodies are constructed as lazy, expensive, and in need of expert control (Groskopf, 2005; Monaghan, 2007). The powerful obesity discourse is also a biopolitical engine fueled by the notion of an "epidemic" (Gard, 2011; Oliver, 2005, 2006; Saguy \& Almeling, 2008). In fact, authors have noted how this notion now serves to legitimize the massive outflow 
of resources, and the surveillance and containment of bodies (Herrick, 2007; Rich \& Miah, 2009). Harwood (2009, p. 15) has suggested that the purported obesity epidemic has generated new forms of disciplinary practices that can be conceptualized as "biopedagogies." Informed by Foucault's notions of biopower ${ }^{1}$ (Foucault, 1994, 1995) and biopolitics ${ }^{2}$ (Foucault, 2008), these biopedagogies revolve around the moral regulation of bios or life (i.e., how to eat, how to move, how to live). Biopedagogies are part of what Foucault would call an apparatus of "governmentality" (2009, p. 108). Evans and his colleagues have suggested that the latter involves managing bodies to both reduce obesity and protect populations from the purported "risks" associated with it (Evans, Rich \& Davies, 2004; Rich \& Evans, 2005a). Wright and Harwood (2009) have further noted that biopedagogies draw on a neoliberal notion of individualism that constructs individuals as at once capable of and responsible for changing their lifestyles through a variety of disciplinary techniques.

In brief, despite its complex ramifications, the dominant obesity discourse has mostly appeared in the guise of a seemingly universal message: exercise more and eat less. This commonsensical message-along with its underlying modern and neoliberal premises - has been recited ad nauseam and has had a number of significant discursive "effects in the real" (Foucault, 1980, p. 237). Individuals from varied social and cultural locations have been impacted by it in diverse and sometimes adverse embodied ways (Evans, Rich, Davies \& Allwood, 2008; Harper \& Rail, 2011, 2012; Jette, 2006, 2009; Norman, 2009; Rail, 2009; Sykes, 2011; Wright, 2009), and it has led to an important biopolitical project: I label this project the "Obesity Clinic."

In the present article, I aim to briefly document the discursive terrain that has given life to the idea of the Obesity Clinic by presenting a series of eight "postcards" that sum up the dominant obesity discourse. Following this exploration, I discuss the birth of the Obesity Clinic and its links to larger phenomena of biomedicalization, bioeconomics and biocultural discourses. Finally, I offer a few reflections about the territorializing nature of this Clinic as well as what it means for subjectivities, individuals, and physical culture in general.

\section{The Obesity Postcards}

Why do I use the idea of a postcard to discuss the current knowledge of the obesity epidemic? I think of the postcard as a simple, efficient picture that proposes to tell the truth about a space and moment while arbitrarily framing a particular reality. It is a scenographic performance that hides those things we would rather not see; a dry fragment of a humid reality, if you like. As an outrageous simplification, the postcard reunites a very complex world in a simple vignette: it proposes shortcuts, summaries. Despite this, the postcard is good enough for many people. Universities often seem like postcard factories. Postcards are recited by intellectual elites and their colors get brighter and brighter, their writing bigger and more cliché, as the postcards make their way to a larger public. The problem with postcards is that they circulate misunderstandings that become truth through repetition.

In the next few pages, I would like to follow in the footsteps of French author Michel Onfray (2010) and use postcards and "counter-postcards" to develop my argument. The counter-postcards reveal the arbitrariness and simplicity of the obe- 
sity postcards. They are not meant to be empirical "corrections" or more authentic representations of the "Truth" about obesity but rather my very partial and admittedly superficial reading of the obesity postcards for the simple purpose of opening a small window on the subversion of their objective assumptions and postulations.

\section{Postcard \#1: Obesity Is a Disease}

Those who circulate the postcard stating that obesity is a disease first need to erase the history of the transformation of fatness into obesity as a "disease" (see Lyons, 2009; Oliver, 2005, 2006). They need to frame the picture in a way that veils the story of those who pushed hard for, and have succeeded in constructing obesity as a disease as well as those who profit from such arbitrary creation, namely mainstream obesity scientists, bariatric surgeons, and the fitness and weight loss industries (see Campos, 2004; Gard \& Wright, 2005; Oliver, 2005). Amounting to an exceptionally industrious obesity postcard factory, mainstream obesity science has adopted a specific language (e.g., calls to "fight domestic terrorists") and instituted a political agenda to purportedly save the nation (Rail, Holmes \& Murray, 2010). The picture frame must also move away from the gigantic mountain constituted of the insurance companies and the pharmaceutical industry since labeling obesity a disease opens up insurance coverage to millions who now need obesity "treatment" (i.e., visits to Weight Watchers, Curves or Jenny Craig) and speeds up the approval of new diet drugs (Gaesser, 2009; Lyons, 2009).

The counter-postcard reveals an interesting story about the profit-oriented motivations of various actors who Mundy has collectively dubbed "Obesity Inc." (2001, p. 12) for unnecessarily medicalizing obesity, distorting statistics on the consequences of growing weights, ignoring the complicated realities associated with being fat, diverting scarce resources, and distracting public health efforts (see also Brownell, \& Horgen, 2003; Campos, Saguy, Ernsberger, Oliver, \& Gaesser, 2006; Herrick, 2007). In this alternative story, obesity science emerges as a tangled web of government lobbies, academia and its research sponsors, service industries, multinational pharmaceutical and agribusiness complexes, the legal-juridical complex, and the insurance industry who all benefit from the idea that obesity is constructed as a disease. For example, the counter-postcard exposes many of the leading obesity researchers as beneficiaries of sizable funding from the pharmaceutical and weight-loss industries. In addition, it discloses the fact that a great number of researchers also manage weight loss clinics or have an economic interest in redefining "unhealthy" weight as broadly as possible. My point here is not to get ideology or biased researchers out of obesity science but rather to get ideology and bias out of hiding: to expose them for who they are by including them in the counter-postcard. Following this, obesity can be reconceptualized not as a simple "scientific fact" or a static bodily condition but rather as a process whereby regulatory norms (e.g., norms related to the Body Mass Index or BMI) materialize fatness into "pre-obesity" (the WHO's preferred term for a BMI between 25 and 30) and "obesity" (i.e., when the BMI is over 30, according to the WHO). This materialization can be revealed as a forcible reiteration of norms and BMI boundaries constructed by science. A counter-postcard posits obesity as a linguistic construction that is unstable, working as it does by always reestablishing boundaries and thus a zone of "abjection." 3 This is a zone inhabited by BMIs 
that signify the unhealthy, the failed, the abject, the obese, or the morbidly obese body. The zone of abjection has moved considerably over time and space: not all countries use the same BMI cut-off points (e.g., in many Asian countries, the BMI threshold for obesity has been lowered from 30 to 25) and the appropriateness of the BMI varies according to age (e.g., the BMI is used differently for children and for older individuals). The moving zone of abjection (across individuals, time and geography) has at times contributed to the purported increase in obesity rates. For example, in the U.S.A., 25 million individuals previously in the "healthy" category found themselves overnight in the "overweight" category because of a lowering of the BMI cut-off point from 27.8 to 25 in 1998 (see Lyons, 2009).

In brief, the counter-postcard presents obesity not as a scientific fact but rather as a discursive "effect" of the dominant obesity discourse. As Boero (2007) has suggested, the negative constructions of fat embodiment articulated in popular discourses are productive of obesity rather than descriptive of it. In parallel, medical professionals who diagnose obesity actually render fat individuals (even if they are otherwise healthy) "diseased" through their proclamation. Indeed, while the BMI is inappropriate for individual diagnosis (it was designed uniquely for population studies), health professionals have come to rely on its apparent numerical authority to diagnose obesity (when the BMI is over 30). To use Butler's (1993, p. 171) term, their medical diagnosis of obesity is a "performative act": it is an authoritative speech that is enforced through laws (around the diagnostic power of medical professionals), dominant social discourses (on obesity and health), and (BMI) norms. Diagnostic declarations are performative (i.e., words do something) as opposed to constative (i.e., words describe something). Indeed, diagnostic statements (e.g., "you are obese," "you suffer from obesity") exhibit the power of discourse and produce the phenomenon (i.e., obesity) that discourse wishes to regulate. In the end, the counter-postcard leads us to ponder the paradox of promoting health via discursive processes that result in more people viewing themselves as sick.

\section{Postcard \#2: Obesity Is Directly Related to Health Problems}

The second postcard associates obesity with health problems. This postcard is extremely popular since studies linking obesity to morbidity and mortality have exploded in the last 20 years (see overviews in Gaesser, 2003c; Gard \& Wright, 2005; Lenz, Richter \& Mühlhauser, 2009; Mark, 2005) and have been widely circulated in the media. In the postcard version, the relationship between obesity and health is linear: there is a direct, positive, and strong causal link between the BMI and morbidity and mortality rates.

The counter-postcard presents a very different picture with a complex U-shape relationship that indicates the negative impact of low weight and anorexia on health and, with the exception of extreme BMI measures, the little impact of higher BMI on morbidity (Campos et al., 2006; Flegal, 2010; Gaesser, 2003c, 2006; Oliver, 2006; Lenz, Richter \& Mühlhauser, 2009; Lloyd-Jones et al., 2009) or mortality (Farrell et al., 2002; Flegal, \& Graubard, 2009; Flegal, Graubard, Williamson, \& Gail, 2005; Gaesser, 2003b; Mark, 2005). The ostensible adverse health consequences of being overweight and obese have not only been exaggerated by those Monaghan, Hollands and Pritchard call the "obesity epidemic entrepreneurs" (2010, p. 37), but they have often been fabricated (Evans et al., 2008). In the U.S.A., for instance, the 
National Center for Health Statistics (2008) has clearly shown that despite increases in obesity prevalence, mortality rates in general as well as mortality from coronary heart disease and stroke in particular, have declined over several decades. To explain this paradox, Gaesser (2009) has suggested that studies showing a link between high BMI and ill health usually fail to control for important variables that mediate that relationship (e.g., socioeconomic status, physical activity, weight cycling, use of diet drugs). Oliver (2005) has compared this to blaming yellow teeth or bad breath (instead of smoking) for lung cancer. Against the mainstream obesity scientists' claims that obesity is often the cause of cardiovascular disease, Oliver and other critical researchers (e.g., Gaesser, 2003c; Campos et al., 2006; Ernsberger, 2009) have noted that socioeconomic status is a powerful predictor of cardiovascular disease across the weight spectrum: fat individuals are often unhealthy because they are often poor. The counter-postcard deconstructs the premises of studies that claim an impact of obesity on mortality rates (Farrell, Finley, McAuley \& Frierson, 2011; Gaesser, 2003b; Mark, 2005). It rather demonstrates no impact (Flegal, \& Graubard, 2009) or a small beneficial impact of being overweight, particularly for women and particularly for older women (see a review in Oliver, 2006). In short, the relationship obesity scientists establish between BMI and health problems seems grossly exaggerated. Burgard (2009) has observed that for studies on the issue, the highest correlation to be found is around $r=.3$. Since this correlational statistic must be squared, this suggests that no more than $9 \%$ of health outcomes is related to BMI. The aim of the present counter-postcard is not to restore "truth" and to produce a list of studies and statistics that contradicts another. Rather, it is to show that a health crisis has been discursively constructed on the basis of an overly simplistic (postcard) version of a very complex and multifaceted reality.

\section{Postcard \#3: Lifestyle Is Directly Related to Obesity}

In the last 100 years, research has focused on the causes of fatness and, invariably, a mechanistic model has been used to explain fatness. Not surprisingly, the postcard emerging from this type of research focuses on the presumed relationship between inactivity, poor diet, and obesity. This "lifestyle" model is deeply entrenched with notions of individual choice: one chooses whether to pursue this lifestyle or that other one and hence one chooses whether to be fat or not. Therefore, one of the most compelling criticisms against the "lifestyle" postcard is that it cuts out from the picture the ways in which social and economic conditions substantially determine one's lifestyle choices. Given the simple finding that socioeconomic status is more related to BMI than any lifestyle factor (see a review of studies in Ernsberger, 2009), we may agree that the postcard tends to de-socialize obesity.

The counter-postcard tells a significantly different story as it attempts to resocialize understandings of fatness and health by underscoring important phenomena such as the impoverishing effects of fatness (e.g., stigma and discrimination impact on education, employment, salary, medical care), the health impact of poor neighborhoods (e.g., more pollution and noise, less access to fresh food or to free and safe outdoor activities) and the magnifying force of gendering, racialization and marginalization processes on fat discrimination and stigma (Boero, 2009; Cohen et al., 2005; Ernsberger, 2009; Lang, \& Rayner, 2007; Puhl, \& Brownell, 2001; Sykes, \& McPhail, 2011). 
Goldberg (2009) has suggested that if the cause of health problems is perceived to be fatness (and that is a big "if" since he is skeptical of the causal link between fatness and illness), and if the cause of fatness is perceived to be unhealthy lifestyles, then the perceived solution is to regulate such lifestyles (e.g., providing incentive for people to be active, regulating school cafeterias, requiring calorie information on menus). In contrast, if the cause of fatness is located at the level of social and economic conditions, policy solutions would seem to fall much closer to ameliorating the conditions that seem to promote unhealthy lifestyles. Against such sociocultural considerations, individual-centered and media-ready explanations dominate the obesity postcards collection, often devaluing and even excluding important considerations around the influence of social structure (Rich \& Evans, 2005b). In sum, one way to subvert the "lifestyle" postcard is to consider the complex etiology and context of obesity. As Sykes and McPhail pertinently conclude: "histories of fat allow us to contextualize past and, by important extension, current understandings of fat in social structures like gender, diasporas and economies" (2011, p. 57).

\section{Postcard \#4: Obesity Is a Question of Personal Responsibility and Individual Risk}

When circulating postcards that de-socialize obesity, it is not surprising that obesity comes to be seen mostly as a personal responsibility. The neoliberal language of individual responsibility speaks loudly to the masses, and both epidemiologists and marketers tend now to focus on individual risk to personal health rather than on population risk (Evans, Rich, \& Davies, 2004; Herrick, 2007; McDermott, 2007; Ross, 2005; Saguy, \& Gruys, 2010). This leads to the aberrations we hear or see in the media on a daily basis. For example, we could use the data from a study conducted by Gelber and her colleagues (2008) that reports measures of obesity and cardiovascular risk among 32,700 American women. The study notes that 414 cardiovascular incidents occurred in older women after 5.5 years (174 nonfatal myocardial infarctions, 182 nonfatal ischemic strokes, and 58 fatal cardiovascular disease cases). Using numbers provided by Gelber and her colleagues, we could roughly estimate the risk of cardiovascular incident as being the probability that in a comparable population of 7,478 obese women (BMI of 30 or higher) and 25,222 nonobese women (BMI less than 30), there would be approximately 120 and 294 incidents, respectively (roughly 16 out of 1000 obese women and 12 out of 1000 nonobese women). The risk ratio (RR) would be $16 / 12$ or approximately $1.4-1$. In the media, unfortunately, we tend to hear the postcard version of reality and so we would most probably hear that an obese woman is $140 \%$ more likely to suffer a cardiovascular incident than a nonobese woman.

This statistic is truly terrifying. A counter-postcard provides a space for challenging such a way of interpreting the data as individual risk cannot be concluded here. An alternative interpretation allows us to understand that less than 3 (16 women over 5.5 years) in every 1,000 obese women have a cardiovascular incident in a given year. This statistic is less frightening especially when we consider that a large majority of cardiovascular incidents ( $86 \%$ in the example here) are not fatal. The counter-postcard also focuses attention on the idea that we would need many more cardiovascular incidents and a huge difference between populations of obese 
and nonobese women to conclude on a significant effect (e.g., not a risk ratio of 1.4-1 but rather something much higher like 10-1 or, as is roughly the case for lung cancer when we look at smokers versus nonsmokers, 30-1).

More than alternative interpretations, the counter-postcard offers a spatial and temporal context for the appearance of a discursive formation that emphasizes personal responsibility and individual risk of obesity. Boero (2007) has documented how the obesity "crisis" has emerged as a way to individualize ill health at a time when the welfare state is being dismantled, and when healthcare access and the social safety net for healthy communities are disappearing. Of course, "neoliberal restructuration"4 most negatively impacts those marginalized "Others" already seen as most at risk from obesity (Evans, Rich, \& Davies, 2004; Herrick, 2007). Individual (postcard) explanations for social problems seem to thrive during times of growing social inequality.

\section{Postcard \#5: There Is a Global Epidemic of Obesity}

Certainly the most popular and frightening postcard is the one concerning the so-called epidemic of obesity. This postcard builds upon the dominant obesity discourse and fuels its biopolitical power through the deployment of the notion of "epidemic." The obesity epidemic postcard has been dispersed in the epidemiological, physiological, and medical literature on obesity in the last ten years and has been recuperated by the media, educational institutions, health and fitness practitioners, and public health officials. The obesity crisis, so the general argument goes, afflicts an increasing number of countries in the world and threatens a global health catastrophe (WHO, 2000, 2011).

Challenging the medical significance of the increase in body weights in many countries in the world, the counter-postcard attracts our attention to the rhetorical changes that have propelled obesity onto the medical world scene. As Gard observed:

What changed around 2000 was the rhetoric. Almost overnight, obesity joined the ranks of famous infections and contagions and was transformed from a slow-moving inconvenience into an agile killer. Apparently respectable medical researchers attempted to make the argument that it spread from person to person and, given time, would reduce life expectancies and match the devastation of plagues, terrorist bombs, rising sea levels and mass species extinction. As an epidemic, obesity now moved in totally new rhetorical circles. A simple twist in the language catapulted it out of the medical B grade, occupied by the likes of toenail fungus and back pain, and into the big league alongside AIDS, cancer and heart disease. (2011, p. 1)

No doubt that via the enlistment of fear and panic, mainstream obesity science has gained authenticity and validity. Miah and Rich (2006) have argued that as a medically and socially authoritative discourse, the obesity epidemic has enabled the mobilization of bodies, the dispensation of resources, and the justification of tactics of surveillance and regulation. In the U.S.A., for example, over 600 obesityrelated bills have been introduced in state legislatures and a Surgeon General has suggested that obesity constitutes a greater threat to the country than terrorism (Tumulty, 2006). In addition to lifting the veil on the biopolitics subtending the rhetorical deployment of the obesity epidemic, the counter-postcard furthers our 
understanding of this epidemic as a postmodern one. Indeed, Boero (2007) has noted that the obesity epidemic is not a traditional epidemic of contagion and mass death. She uses the term "postmodern" to qualify a phenomenon that lacks a clear pathological basis and gets cast in the language and fear of traditional epidemics. Since the existence (or even the "spread") of fatness cannot alone fuel the panic around the epidemic, Boero argued that it is accompanied by a shift in the meaning of fatness. Borrowing from Treichler, she suggested that along with the biomedical aspect of the epidemic, there exists a parallel "epidemic of signification," (1999, p. 1) where fat bodies are resignified as out of control, threatening, dangerous. According to Boero, the emergence of postmodern epidemics also indicates a transformation in the thinking about public health: away from the public and onto the individual. In the case of obesity, the concern is not only for obese individuals but also individuals "at risk" (i.e., everyone). On the discursive terrain of the obesity epidemic, individual blame is thus placed for obesity and preobesity. Gard and Wright's (2005) classic book of critical obesity scholarship, The Obesity Epidemic: Science, Morality and Ideology, charts the remarkable journey of the obesity epidemic and elegantly subverts the claims of mainstream obesity science. Up-dating this work and noting that the predictions of a health apocalypse have not materialized, Gard's (2011) new work, The End of the Obesity Epidemic, provides further viewpoints for counter-postcard enthusiasts.

\section{Postcard \#6: (When It Comes to Obesity) Experts Know Best}

As a discursive effect of obesity discourse and the rhetorical strategy of a catastrophic obesity epidemic, obesity scientists and clinicians have acquired the ability to circulate yet another postcard. The latter makes clear that they, along with other obesity "experts," know the "truth" of obesity and have the moral and intellectual authority to label it a disease and prescribe treatment.

The counter-postcard allows a different viewpoint on such phenomena. Using Foucault's formulation of the modern confessional (1978), we can think about how dominant discourses are often recited by an authority figure that disciplines subjects into both agreeing to a regimen of truth and taking part in processes leading to "salvation." (p. 62). For Foucault, the modern confessional is similar to the Christian confessional in that it seeks to provide its subjects with relief from the weight of their waywardness while keeping them within the confines of its belief system. Unlike the Christian confessional, however, the modern confessional is not tied to the Church but is, instead, tied to a number of power/knowledge formations. In the same way the penitent seeks salvation from the priest, for instance, the patient seeks treatment from the psychologist or psychiatrist. Using a biopedagogical mechanics similar to Foucault's "confessions of the flesh" (p. 19), I argue that fat subjects are also encouraged to engage in confessional practices so that they can be rescued, rehabilitated, and saved.

As I have discussed in more detail elsewhere (Rail \& Lafrance, 2009), fat subjects' salvation requires three stages: First, an authorized confessor needs to extract a "confession" of obesity; second, there needs to be a conversion to the truth of the dominant obesity discourse; and third, the expert needs to code a "new life" for the obese subject. Obesity scientists and clinicians are presumed to know the "truth" of obesity and, as confessors, they are authorized to "gaze" (Foucault, 1994, p. 9) 
at fat bodies in ways that reproduce their power/knowledge. In the confessional encounter, the fat subject is often seen simply as an object forced to reveal itself and the confessor's gazing negates the confessing person's subjectivity. Indeed, the confessor needs not interact with a thinking subject; rather the fat body appears to speak for itself. As "obesity" is confessed by the body (the body "offers" its BMI under the watchful gaze of the confessor), then emerges the need for conversion: the confessor (more often a male "expert") must convince the subject (more often a plump female) of the truth of obesity discourse. Having convinced the subject of this truth, the confessor is in a position to convince her that he, as expert, knows best, and that she must change her way of life and redirect the course of her body, her needs, her desires, and her life. Evans and Colls (2009) have documented this latter process and questioned the justification of an obesity politics focused on the BMI given the BMI's inability "to capture the fleshy, material, and experiential bodies of those individuals involved in the process of measurement" (p. 1051). To be sure, the confessor's authority and discursive strategy lie at the very heart of the subject's conversion: they greatly account for why she is brought to believe such truths about her body and act accordingly. The confessor converts the subject by putting a purported scientific objectivity in the service of a project of "deterritorialization" and "reterritorialization" (Deleuze \& Guattari, 1987, p. 54). Deleuze and Guattari see territorialization in terms of the forces of the social impinging on individuals and constructing subjectivities via an act of interpretation. Every inscription by the forces of the social is a deterritorialization of territory and a reterritorialization in some new patterning. For instance, capitalists deterritorialize products into commodities and reterritorialize labor as wages. In the present case, we could say that the confessor deterritorializes the fat subject according to the normative obesity discourse, reterritorializing her as "obese" and "diseased." In the end, the confessor's project of deterritorialization and reterritorialization aims to turn the subject's body from soft to "hard" and from deviant to productive and "docile."

Within a counter-postcard, then, Foucault's notion of the confessional represents a useful way of exploring how the fat subject is formed in and through a range of enunciative practices. In particular, it enables us to probe more deeply the question of how obesity-related speech-acts (e.g., the expert's diagnosis of obesity) condition the subject's most basic understanding of her embodied self. It also demonstrates the extent to which one's obesity is not simply communicated, but is in fact materialized through a (bodily) confession extracted by the expert. In the case of obesity, then, the confessional encounter is performative (Butler, 1993): it produces what it names.

\section{Postcard \#7: Weight Loss Is the Right Prescription for Obesity and It Will Improve Health}

Powerful authorities (e.g., CDC, IOM, WHO) reiterate the dominant discourse regarding excess weight and how it leads to escalating morbidity and mortality. The resulting corollary is the popular postcard reproducing the notion that weight loss is the right prescription and that it will improve health. This prominent postcard finds its way in clinical guidelines (ACOG, 2005, IOM, 2009; Lau et al., 2007; $\mathrm{NIH}, 1998$ ), in social institutions and notably the mass media (Boero, 2007; Gard, 2009; Rich, 2010, 2011; Saguy \& Almeling, 2008), and in ordinary citizens' nar- 
ratives in the quotidian (Burrows, 2009). Thanks to the rhetoric of the impending epidemic, citizens are encouraged to take steps to protect themselves and those around them and thus prevent the spread of the "disease." Maintaining or achieving a "normal" weight becomes not only a personal responsibility but a civic duty. In such a context, immense social pressure is exerted on individuals who have "excess" weight. As Murray suggested:

The responsible citizen, therefore, is both literally and figuratively, an active citizen. To combat the spread of disease that characterizes an epidemic, citizens are called to action; in the instance of obesity, this action necessarily entails one's participation in strict exercise and diet regimes [. . . ] It is interesting, therefore, that obese citizens are most often understood as fundamentally inactive: indeed, it is their inaction that is regarded as causing their diseased state [. . . They] are positioned in this way as recalcitrant, without conscience or respect for their public duty of controlling their disease. (2008, pp. 9-10)

Contra the above (postcard) version of the obesity story, some authors have reported how actively people have been involved in weight loss. In the U.S.A. alone, Gaesser (2009) has estimated that over 85 million individuals were attempting to lose weight in 2005. In addition, Chou, Saffer and Grossman (2004) have suggested that a significant portion of the population's weight gain can be attributed to smoking cessation, which runs counter to the assumption that weight gain is evidence of moral laxity, lack of action to improve one's health, and a harbinger of declining overall health. But the findings that weight loss is overwhelmingly the prescription for obesity and that a huge portion of the population actively engages with such prescription is no reason to rejoice. First, authors have suggested that weight loss is ineffective (Lyons, 2009) and nonpermanent (Campos et al., 2006). In fact, it has been argued that permanent weight loss is an "oxymoron" (Gaesser, 2009 , p. 37), since there is currently no method available to produce significant long-term weight loss. In that regard, Brownell (2010) has called obesity the "great humbler" suggesting that "some of the field's brightest scientists have attempted to subdue obesity by treating it, but now, after decades of work, treatment gains remain small, maintenance is poor, and the field produces effects far below what patients want or expect" (p. 717). Second, professionals who prescribe treatment must take responsibility for the clinical care of their patients and for monitoring efficacy and safety. In the case of obesity, however, weight loss is the preferred treatment but there is extremely limited efficacy in addition to a tendency to downplay treatment risks and failures (Lyons, 2009). Third, Boero (2007) has written about how risky weight-loss surgeries originally designed to treat extreme cases of "morbid" obesity - they all involve sealing off or removing part or all of the stomach to limit food intake as well as bypassing parts of the intestines to prevent food absorption-have been normalized and are increasingly advertized and prescribed. All in all, one has to wonder whether the treatment prescribed for obese individuals is driven more by the will to discipline and normalize bodies than by the will to improve health.

With regards to this last point, a number of scholars have indeed questioned the pathologization of obese individuals (Murray, 2007, 2008; Oliver, 2006) when direct links between obesity and health have failed to materialize (see counterpostcard \#2) and when turning obese and overweight people into so-called "normal 
weight" individuals has not been demonstrated to improve their health. Campos and his colleagues (2006) have argued that since long-term weight loss in statistically significant cohorts has remained elusive, the claim that long-term weight loss improves health remains unverified. However, what should appear in the counterpostcard are the findings that overweight or obese persons trying to lose weight without success still benefit from a reduction in the rate of mortality equal to those who are successful (Gregg et al., 2004) and that weight loss increases the mortality hazard ratio while obese people with a stable weight experience no increase (Diaz et al., 2005). Furthermore, authors have found most weight-loss strategies to have serious side effects and to potentially lead to unhealthy practices such as weightcycling (Campos, 2004; Stice et al., 1999) and eating disorders (Clift \& Wright, 2010; Evans, 2006; Rich \& Evans, 2005a, 2005b) as well as to poor body image, low body satisfaction, and low self-esteem (Beausoleil, 2009). As Cohen and his colleagues have suggested, "the persistent drumbeat of obesity oversimplifies a complex issue" (2005, p. 154). Postcard \#7 acts similarly by placing the blame on the shoulders of individuals and by distracting us from seeing the larger picture and realizing that weight loss fails, often miserably, to improve the health of individuals.

\section{Postcard \#8: Targeting Women and "Unhealthy Others" Is a Key Strategy to Fight Obesity}

The last postcard is interesting because it gives us hints about the nature of the biopolitical project associated to the obesity story. Though everyone is "at risk" for obesity, Boero (2007) has aptly demonstrated how the epidemic is gendered in that women have always been the central targets of the weight-loss and cosmetic surgery industries and are held to a more rigid standard of body size than are men. Bordo (1993) and other feminists (e.g., Bartky, 1990; Braziel \& Lebesco, 2001; Garland-Thomson, 2005; Grosz, 1994; Murray, 2007) have documented the biopedagogical mechanics underlying the maintenance of oppressive feminine norms, but the rhetoric of the obesity epidemic is now justifying such norms via concerns for individual risk and public health.

The counter-postcard discloses such neocolonial tactics and draws attention to the regendering and racialization of fatness. Aphramor and Gingras (2009) have charted the disappearance of feminist discourse from dietetics and shown how consumerist and decontextualized understandings of health and fatness occlude issues of power and gender. These authors argued that gender and race do matter as women (and particularly racialized women) are fatter and suffer more from fat prejudice and poor nutrition, while obesity scientists and health "experts" are more often lean white males. The regendering of fatness also comes through women's bodies and mothering capacities (Bell, McNaughton, \& Salman, 2009; Warin, Turner, Moore, \& Davies, 2008). Jette and Rail (submitted) suggested that the process starts early as pregnancy has recently been identified as a major contributor to the obesity epidemic. In this new type of "mother blame," it is argued that women are beginning pregnancy overweight, gaining too much weight during pregnancy, and failing to lose the extra weight postpregnancy (Catalano, 2003; Murphy Paul, 2008; Reece, 2008; Symonds \& Gardner, 2006). Surfing the wave of the rhetoric of epidemics, scientists and commentators have written about the "vicious cycle of maternal and childhood obesity" (Catalano, 2003, p. 3505) that is "rapidly spiraling upwards" 
(Reece, 2008, p. 23). The anxiety is such that medical organizations (e.g., IOM, 2009; NIH, 1998; SOGC, 2010) are advising women to "become fit and have a normal BMI before they consider pregnancy" (Davies, Maxwell \& McLeod, 2010, p. 172; emphasis added). This new form of eugenics is not without connections to the fact that racialized women-as racial "Others" and as m/Others — are also seen as a key point of intervention into the so-called epidemic. In her excellent piece on "fat kids and working moms," Boero (2009, p. 113) has shown how women-particularly poor and racialized women - are targeted as an entry point into specific cultures and as potential preventers of obesity. Poor and racialized women are blamed as mothers passing "bad" eating habits onto their children and as active agents in the reproduction of "unhealthy" cultures. In such a racist and neocolonial perspective, Boero concluded, simplistic and essentializing caricatures of "ethnic" cultures are targeted for intervention while macro-level frameworks that consider the social determinants of health are completely overlooked.

\section{The Birth of the "Obesity Clinic"}

If we pile up the postcards so far, the following message emerges: (1) obesity is a disease; (2) people choose obesity; (3) obesity causes health problems; (4) those "at risk" need monitoring; (5) especially in a time of epidemic; (6) but experts know best about obesity; (7) so let's follow their weight loss prescription; and (8) target women and unhealthy Others. The postcards and their message are so omnipresent that they have become part of our imaginary and indeed are calling for the birth of something like an "Obesity Clinic." I use this expression to pay homage to Foucault's (1994) work but space prevents me here to engage with a Foucauldian-style archeology. However, I wish to argue that the birth of the Obesity Clinic may be understood at the nexus of three interrelated and larger phenomena: biomedicalization, bioeconomics, and biocultural discourses surrounding obesity. ${ }^{5}$

With regards to biomedicalization, Murray and his colleagues (2007) have argued that the health care and research industries constitute a complex system enmeshed with innumerable government lobbies and agencies, academic health sciences and their research sponsors, multiple public and private stakeholders, and the pharmaceutical and insurance industries, to name just a few. For the average person, this system can be incomprehensible, if not barely navigable, and it is not farfetched to imagine the individual disappearing into it, subject to its "discipline" (Foucault, 1995, p. 137). The multiple nodes of influence and control are not simply the expansion and reticulation of medical authority and practices into new realms; together, they represent a new way of understanding the relation between medicine, health, and life itself (Murray et al., 2007). I thus want to borrow from Clarke and her colleagues and dub this phenomenon "biomedicalization" (Clarke, Shim, Mamo, Fosket, \& Fishman, 2003, p. 23). Biomedicalization is characterized by the new political economic valences of biomedicine, the rise of risk surveillance, and the medicalization of risk factors, to name a few elements.

For the second phenomenon, bioeconomics, we can say that it results from mapping the process of biomedicalization seamlessly onto the political economy of neoliberalism. In turn, neoliberal political economic discourses feed on and supplement biomedicalizing discourses. Both types of discourse (i.e., bioeconomic and biomedicalizing) demand greater efficiency and greater economy in the face 
of dwindling public resources and soaring health care costs. Both discourses are circulated by an influential group of bariatric and weight loss surgeons, diet doctors, weight loss practitioners, mainstream obesity scientists, public health educationists, drug and insurance company representatives, and other laborers associated with the obesity factory. In biomedicalizing and bioeconomic discourses, the individual becomes a producer-consumer in the sense that she is imagined to produce the satisfactory thinness and health that she will enjoy and "consume." Under neoliberalism, the subject's own self-improvement is internalized as a moral duty to one and all (Miller \& Rose, 2008). The person who is preobese or obese accrues a social debt that must be redeemed by locating herself within compensatory discourses and praxes that are both rhetorical and corporeal.

The third phenomenon, biocultural discourses, is linked to the first two in that biomedical and bioeconomic discourses work together to inform much wider cultural perceptions of the body and health. From academe and its research granting bodies to hospital ethics review boards and the medical insurance industry, dominant discourses are purchased wholesale from the corporate sphere, an Orwellian catalog that includes the "client-based" mantra, key performance indicators, outcomes, evidence-based medicine, best practices, clinical guidelines, knowledge mobilization, and commercialization (Murray, Holmes \& Rail, 2008). "Clients" are encouraged to conceive of themselves in entrepreneurial terms: they begin to relate to their own bodies and genetic material in instrumentalist and economic vocabularies. Think here about "biocapital" (Sunder Rajan, 2006, p. 7) or the trend of "biobanking" (Mitchell \& Waldby, 2010, p. 330). In brief, biomedicalizing and bioeconomic discourses join biocultural discourses to shift popular perceptions toward the acceptable (thin) body and the ways in which we should understand our bodies and our selves. Such bioprocesses invite a blind obedience to scientific authority, to the "truth" of science, to the ideological political economic coordinates of neoliberalism, and to the cultural science fiction of the "truths" of obesity as a disease and an epidemic.

\section{The Obesity Clinic: A Global Apparatus of Capture}

As a biopolitical project, the Obesity Clinic engages in a global effort to discipline the masses and to develop good, productive "bio-citizens" (Halse, 2009, p. 50) who will not burden health care and other neoliberal systems. The sheer magnitude of this project requires a different kind of clinic and this is why I have insisted on using capital letters to identify the Obesity Clinic. This Clinic is not an ordinary clinic. What I would like to argue is that because of bioprocesses such as biomedicalization, bioeconomics, and the circulation of biocultural discourses, the Obesity Clinic can be understood as a clinic without borders. This polymorphous clinic has territorialized our living and dining rooms, our houses, our physical education classes, our schools and school yards, our own departments within universities, our sport fields, our media, in brief, our entire "physical" culture. As obesity preventative measures and obesity treatments have become commodified, we have witnessed an even louder cacophony of allegedly authoritative voices reciting the dominant obesity discourse and telling people what to do to be thin and healthy (e.g., exercise physiologists, physical educators, kinesiologists, staff in sports or fitness centers, coaches, parents). We have also seen an explosion in the number of individuals 
according themselves the right to diagnose obesity and to prescribe treatment. Of course, many (pseudo) doctors without borders have been heavily recruited by popular media as obesity factory workers. Scholars have noted this to be the case for films, magazines, weeklies, newspapers, television programs (53 medical dramas in the U.S.A. and Canada alone) and other television shows such as news, children's programs, talk shows, primetime shows, reality shows, makeover shows, and weight loss and bariatric surgery infomercials (Boyce, 2007; Campo \& Mastin, 2007; Giles, 2003; Himes \& Thompson, 2007; Holmes, 2009; Inthorn \& Boyce, 2010; Kim \& Willis, 2007; Robinson, Callister \& Jankoski, 2008; Roy, Faulkner \& Finlay, 2007; Saguy \& Almeling, 2008; Saguy \& Gruys, 2010; Whitehead \& Kurz, 2008; Wilson, 2005; Ye \& Ward, 2010). As a global and all-pervading entity, the Obesity Clinic uses biopedagogies and re/produces the obesity discourse by involving multiple points of collusion with variously positioned obesity entrepreneurs. For example, the obese body is displayed and spectacularized (Braziel \& LeBesco, 2001) in an attempt to sell a putative "solution" to obesity through the fitness, diet, weight-loss, pharmaceutical, cosmetic, and bariatric surgery industries (Atkinson, 2008; Lyons, 2009; Monaghan, 2008; Rail \& Lafrance, 2009).

Given the manner in which the Obesity Clinic functions, it could be conceptualized as an "apparatus of capture" (Deleuze \& Guattari, 1987, pp. 437-448). Indeed, like other entities using biopedagogical mechanics related to health (see Holmes \& O'Byrne, 2010), the Obesity Clinic constitutes an evasive and invisible system of order. The Deleuzian concept of apparatus of capture might bring one to imagine a rigid device assuming control by force, but it rather involves a form of architecture without structure (Patton, 2005) that invites certain types of behavior via social routes such as risk-aversion, desire for responsibility, and aspiration to be (seen as) a mature and moral individual (O'Byrne \& Holmes, 2007). The Obesity Clinic is thus a system where individuals willingly and proactively reproduce their own capture. It serves as a self-surveillance medium that presses individuals toward monitoring themselves. Being overweight or obese is marked as a failure while the thin body is given recognition as reflecting the control, virtue, goodness, rationality, and self-discipline of perfect neoliberal subjects.

\section{The Obesity Clinic: Regulating the Abject}

The Obesity Clinic has territorialized our semiotic environment and so it is no surprise that so many films (e.g., The Nutty Professor, Norbit, Shallow Hal, Hairspray, Fat, Sick, and Nearly Dead) or television shows (e.g., Nip/Tuck, Gray's Anatomy, The Half-Ton Mom, Extreme Makeover: Weight Loss Edition, Village on a Diet, Heavy, More to Love, Drop-Dead Diva, Ruby, The 650-Pound Virgin, One Big Happy Family, Huge, More To Love, Mike and Molly, Ruby, Drop Dead Diva, I Used to Be Fat, Fat Actress, Making the Curve) follow the well-known Foucauldian script and offer evidence of Foucault's (1995) thesis that modernity-and the disciplinary power that characterizes it-is more about managing life than threatening death. Power is brought to bear on bodies not for the sake of punishing them but for the sake of rescuing, rehabilitating, and saving them. Foucault's formulation of the confessional is also useful as it allows us to think critically about the disciplining of both the television shows' characters and viewers. Most shows finish well, and protagonists end up with a new way of life and a new "hard" body. A few shows 
finish not so well for some protagonists (e.g., the Huntington schoolchildren participating in Jamie Oliver's Food Revolution; some of the participants in Village on a Diet; Momma Boone in Nip/Tuck, the not so Biggest Losers) and present carefully constructed "evidence" (Holmes, Murray, Perron \& Rail, 2006) regarding the negative consequences of the obese protagonists' resistance to the dominant obesity discourse (Rail \& Lafrance, 2009). These characters are publicly punished for their soft body and bad life. In this way, some fat protagonists are facing both modern and premodern power: they are both disciplined and punished.

Ringrose and Walkerdine (2008) have suggested that while many television shows, Internet sites, and media productions are invested in the fashioning of a neoliberal bodily culture, women have often been the targets of the biopolitical projects of bodily improvement. A number of authors have noted that in producing female biocitizens, what is produced is more often than not a neoliberal femininity that is bourgeois, yet coded universal, normal, and attainable for all (Hey, 2005; Skeggs, 2005; Walkerdine \& Ringrose, 2006; Ringrose \& Walkerdine, 2008). Bourgeois feminine characteristics are idealized and then taken as normal through a pathologization of working class women and mothers as threats to the moral order. Unruly femininities are thus marked as "abject" (Kristeva, 1982, p. 13). The abject threatens life and it must be radically excluded from the body and deposited on the other side of an imaginary border that separates the self from that which threatens the self. Indeed, the abject is an "uninhabitable" subject position as Butler (1993, p. 3) would say, eliciting shame and disgust that must be cast outside the sense of self and identity. In multiple other examples of our contemporary physical culture, disgust operates through classed processes of abjection. The mechanics at play work to elicit disgust of working class women, particularly when they are marked as working class through their (sedentary) lifestyle, (trashy) clothing, and (excessive) flesh. But abjection does not only maintain boundaries and social regulations. As Ringrose and Walkerdine argued, it incites desire to change the self: "What has intensified in our neo-liberal, individualizing times is the psychological imperative to improve and transform the self through the ready resources made available in self-help culture which dominates popular culture" (2008, p. 235). Indeed, experts offer the self advice not only on how to live but also on how to live better: that is, optimally, efficiently, and productively (Rose, 1999). The struggling self can choose to seek advice and, in doing so, subdue its suffering. The self is bound to and propelled by the project of its own identity. As a result, the self is engaged in a life-long process of assessing and improving its weight and wellbeing through monitoring and management in accordance with free market lifestyle options.

The concept of the "make-over" is not new and neither is Foucault's idea of salvation through confession, conversion, and codification of a new life. However, these incitements have intensified enormously and work in important ways to normalize the contemporary neoliberal ethos of continuously maximizing, bettering, and reinventing the self, but in specific ways marked by gender, class, sexuality, disability, age, and race. This reinvention of the self is at play concomitantly with the drama surrounding the question of whether it is possible for white bourgeois knowledge coded as "expert" to transform abject subjects into appropriate subjects. Skeggs (2005) has noted that while shows often offer a narrative of transformation, many preclude this possibility in a storyline attesting to the subjects' tastelessness, "pathological" culture (p. 976), and "bad choices" (p. 974). The high risk of failure 
and the ever-present uncertainty of success operate in a way such that shows like Biggest Looser, Nip/Tuck, Extreme Makeover, Village on a Diet, and so many others create suspense and drama for viewers and remain favorites within our Western physical culture.

\section{In Conclusion}

In this article, I have followed in the footsteps of Michel Onfray (2010) and presented a series of postcards to summarize the dominant obesity discourse and, more generally, to document the discursive and rhetorical terrain of the "obesity epidemic." I have also offered counter-postcards to destabilize the current regimen of truth and dispute the postcards' objective postulations. Having discussed the birth of the Obesity Clinic, I have characterized it as a biopolitical project to discipline the masses and develop productive neoliberal biocitizens. I have noted how the Obesity Clinic has gone global in the sense of territorializing the spaces we occupy and experience in our day-to-day life. Hinting at the ways in which racism, sexism, heterosexism, ableism, agism and all manners of marginalization are inherent in the Obesity Clinic's regulation and abjection of unruly bodies, I have suggested that the expansion of medical authority and practices into new social realms is transforming the Obesity Clinic into an "apparatus of capture" invested in and sustained by biocultural discourses and the phenomena of biomedicalization and bioeconomics.

This leads me to a few concluding comments. First, it is crucial to have healthy skepticism vis-à-vis the current mainstream research on obesity, the ways in which the disease of obesity has been socially constructed, and the ways in which the rhetoric of impending epidemics has been deployed to discipline subjects, particularly women, racialized women, working class women, and entire classes of marginalized "m/Others." By associating weight/obesity with health and prescribing and/or engaging with weight loss, all of us may be creating one of the biggest iatrogenic disasters of our times. Concomitantly, I think that rather than repeating the mantra of "obesity" or "weight," it would be more useful to deconstruct the lifestyle model of disease and the idea of personal responsibility for one's health. This deconstruction should include healthy skepticism with regards to microlevel and privatized solutions to public health problems, particularly when they are promoted by Big Pharma and other Obesity Inc. actors that stand to profit from such solutions. Interest in health and wellbeing should lead us to focus on important (i.e., social) determinants of health and to work with communities to create healthy environments and push for progressive social changes.

Second, I consider the dominant obesity discourse as well as the Obesity Clinic to be very seductive entities for those who have practical and/or academic interests in physical culture. Sustained by biocultural discourses, the Obesity Clinic appears to safeguard the proper treatment of autonomous persons, offering them the tools for self-surveillance and self-regulation so that they can become entrepreneurial managers in the development and maintenance of their thinness and health. In reality, however, the individual is increasingly tied to fitness, nutrition and health research and industries, systems of health care and daily life management, and a cadre of medical and other authorities increasingly inculcated into a regimen that ultimately hijacks the subject in the guise of freeing it (Miller \& Rose, 2008; 
Novas \& Rose, 2000; Rose, 2006). Some have referred to Foucault's notion of the "technologies of the self" (1988, p. 18) to describe the multifarious ways in which subjects have attempted to develop their "hard" bodies, completely occluding the idea that such technologies would also require the development of a reflexive self capable of unmasking the territorializing project that subtends the production of the "hard" neoliberal subject.

Third and last, I believe that we need better research on fatness. We must get out of the research loop that prohibits other ways of thinking about the body, physical culture, and health. We need to resocialize the body and health. We need to get past humanist or strictly discursive understandings of the subject and consider how agency is located between free will and "discursive marionettes," to use Hardin's (2001, p. 16) expression. We need to go past questions such as: Is this body obese? How can we reduce this obese body? or How can we use sport or physical activity to reduce this obese body? Instead, we must consider questions such as: How have normalizing truths been constructed around the fat body? For whom? For what purposes? How are master discourses producing particular individuals? How do individuals introduced into (preobese or obese) categories negotiate or refuse those subject positions? Given that language constructs reality and the self, how can normalizing discourses around obesity be exposed and resisted? How can feminist, queer, and disability theories contribute to such resistance and offer new concepts to think about the body, fatness, physical culture, and health? How can the creative power of language be recruited in the development of other, noninstrumental, nontherapeutic ways of looking at sport, physical education, fitness, and physical activity? How do we resist the deterritorialization and reterritorialization of physical culture by the Obesity Clinic? These questions and many more require that we conceptualize research as work that unsettles existing social formations. Subversive research enables us to conceptualize the interconnectedness between individual subjectivities and broader cultural and historical processes which, in turn, should provide the backdrop from which to generate discourses of resistance that contest current notions of obesity, health, and physical culture.

\section{Notes}

1. According to Foucault (2009), a transformation in the exercise of power emerges in the 18 th century with the birth of liberalism. Foucault associates liberalism to a form of government that attempts to maximize its effects while minimizing its costs, following the industrial model. Liberal thought centers on populations and how to control life to better manage the labor force. But to take charge of life and govern the political and economic body of an industrializing society, power needs new processes. Power must be increasingly less the power to put to death (sovereign power) and increasingly more a positive and productive power to intervene to "make live." "Biopower" is the term Foucault (2009, p. 1) uses to refer to modern states' new focus on life through the subjugation of bodies and the control of populations (e.g., the regulation of customs, habits, reproductive practices, family, sexuality, hygiene, well-being, health). Foucault's understanding of biopower can be contrasted to that of Agamben (1993) who brings Foucault's analysis on the very terrain that the latter had wanted to break from: the field of sovereignty. For Foucault, biopower clearly implies a redefinition of power that allows one to grasp power outside of the sovereign and in the interstices where it was undetected. But Agamben (1993) transposes biopower into sovereignty's architecture and links it to a "bare life" (p. 100), that is, a life deprived 
of any rights that can be terminated with impunity. Agemben invokes biopower to think political space in its entirety, which thus functions according to the matrix of the "camp"-a space that is opened when the state of exception begins to become the rule, a space where detainees are placed outside the law and reduced to bare life. Early on, Agamben (1993) wrote about the concentration camps of World War II and more recently, he has given Guantánamo Bay as an example of the "state of exception" (Agemben, 2005, p. 2). Agambem's observation is that modern states increasingly suspend their democratic principles so that the rule of law is routinely displaced by the state of exception and people are increasingly subject to state violence. Both Foucault's and Agemben's understandings of biopower are useful. However, Agemben informs us of specific political mechanisms that cannot represent the entirety of political space. The Foucauldian notion is more pertinent in that regard and allows us to explore phenomena related to the regulation of weight and health.

2. For Foucault, modern states' concern with fostering the life of the population centers on the poles of discipline and regulatory controls. While he saw the former as an "anatomo-politics" (1990, p. 139) that mostly applies to individuals, he uses the term "biopolitics" (2008, p. 317) to speak of the latter, as they mostly apply to populations. Foucault's concept of biopolitics is closely related to his concept of biopower and signals the expansion of power beyond the traditional boundaries of the state and the normative modes of domination to touch every aspect of life ("bio" is the Greek root for "life"). Biopolitics, thus, refers to a style of government that regulates populations through biopower. The term "biopolitics" has been used by other theorists before and after Foucault, and its meaning is not uniform. Hardt and Negri (2004), for instance, have extended Foucault's ideas by suggesting that "immaterial" productions (e.g., ideas, knowledge, affective relations, forms of communication) are also biopolitical-a theoretical development that moves information, communication, and social relations to the center of politics. This development is interesting in as far as it does not challenge Foucault's contention that biopolitics is less about punishment and death and more about the production of life. In contrast, Agamben's (1993) formulation of biopolitics is associated to the administration of "bare life," and its ultimate incarnation is the concentration camp within which individuals are stripped of everything, including their right to live. While Agamben's claim (that the model of the camp is the biopolitical mode) is pertinent for the analysis of contemporary episodes in many Western countries, it does not account for one important point: the threat of violence and death is only one among many forms of biopower today.

3. I borrow here from Julia Kristeva who speaks of "abjection” (1982, pp. 1-2) and of places inhabited by abjected things or beings. I use her notion of abjection to suggest that we experience both fascination and repulsion toward obese bodies and particularly toward extremely obese bodies. We are disgusted because we face something which is usually cast out of our cultural world, something that has come to symbolize disease, immorality, gluttony, sloth, failure, loss of control, danger, or degradation. To confront an obese body is to confront the reality that all of us are at risk for becoming obese. The obese body is seen as an abject body that inspires fear and anxiety since it is an abject site of identification; a receptacle for everything we detest in ourselves. As Kristeva suggested, abjection is always done to the part of ourselves that we exclude.

4. By "neoliberal restructuration," I mean the process whereby large corporations have strengthened their political platform and their role in the radical "adjustment" of modern states. While the Keynesian state was designed to protect populations from the negative impact of foreign capital and external forces, state power is increasingly concentrated in organizations closely involved with the world economy. Government organizations that deal with the needs of the population are now of secondary importance. Restructuration means that the state's premier objective is now to establish favorable conditions for multinational corporations' investment and competitiveness. The lines between corporate governance and national governance having blurred, we witness the corporate colonization of political agendas. As Giroux has aptly noted, such neoliberal development has resulted in the state evading its social responsibilities and shifting them to the individual: "the public and private policies of investing in the public good are dismissed as bad business, just 
as the notion of protecting people from the dire misfortunes of poverty, sickness, or the random blows of fate is viewed as an act of bad faith" (2007, p. 308).

5. For a longer and better contextualized discussion of the processes of biomedicalization, bioeconomics, and biocultural discourses, see Rail, Murray and Holmes (2010).

\section{Acknowledgments}

This research was supported by the Social Sciences and Humanities Research Council of Canada as well as the Canadian Institutes of Health Research.

I would like to express my gratitude to Lisette Burrows (University of Otago) and Jan Wright (University of Wollongong), without whom this research would not have been possible, as well as to other colleagues and members of my research team who, over the years, have provided invaluable input into the research program and the thinking behind this article: Natalie Beausoleil, Sylvie Fortin, Margaret MacNeill, Dave Holmes, Stuart Murray, Alex Dumas, Annie Pouliot, Zeina Abou-Rizk, Emma Harper, Morgan Seeley, Kyoung-Yim Kim, Tammy George, Shannon Jette, Haïfa Tlili and Moss Edward Norman. My thanks also go to the anonymous reviewer and the Editor who provided helpful feedback on an earlier draft of this manuscript.

\section{References}

Agamben, G. (1993). Homo sacer: Sovereign power and bare life. Stanford, CA: Stanford University Press.

Agamben, G. (2005). State of exception. Chicago: Chicago University Press.

American College of Obstetricians and Gynecologists (ACOG). (2005). Committee opinion number 315: Obesity in pregnancy. Obstetrics and Gynecology, 106(3), 671-675. doi:10.1097/00006250-200509000-00054

Aphramor, L., \& Gingras, J. (2009). That remains to be said: Disappeared feminist discourses on fat in dietetic theory and practice. In E. Rothblum \& S. Solvary (Eds.), The fat studies reader (pp. 97-105). New York: New York University Press.

Atkinson, M. (2008). Exploring male femininity in the 'crisis': Men and cosmetic surgery. Body \& Society, 14(1), 67-87. doi:10.1177/1357034X07087531

Bartky, S.L. (1990). Femininity and domination: Studies in the phenomenology of oppression. London: Routledge.

Beausoleil, N. (2009). An impossible task? Preventing disordered eating in the context of the current obesity panic. In J. Wright \& V. Harwood (Eds.), Biopolitics and the "obesity epidemic": Governing bodies (pp. 93-107). New York: Routledge.

Bell, K., McNaughton, D., \& Salman, A. (2009). Medicine, morality and mothering: Public health discourses on alcohol exposure, smoking around children and childhood overnutrition. Critical Public Health, 19(2), 155-170. doi:10.1080/09581590802385664

Boero, N. (2007). All the news that's fat to print: The American 'obesity epidemic' and the media. Qualitative Sociology, 30, 41-60. doi:10.1007/s11133-006-9010-4

Boero, N. (2009). Fat kid, working moms and the "epidemic of obesity": Race, class and mother blame. In E. Rothblum \& S. Solvary (Eds.), The fat studies reader (pp. 113-119). New York: New York University Press.

Bordo, S. (1993). Unbearable weight: Feminism, Western culture and the body. Berkeley: University of California Press.

Boyce, T. (2007). The media and obesity. Obesity Reviews, 8(s1), 201-205. doi:10.1111/ j.1467-789X.2007.00342.x

Braziel, J.E., \& LeBesco, K. (Eds.). (2001). Bodies out of bounds: Fatness and transgression. Berkeley: University of California Press. 
Brownell, K.D. (2010). The humbling experience of treating obesity: Should we persist or desist? Behaviour Research and Therapy, 48, 717-719. doi:10.1016/j.brat.2010.05.018

Brownell, K.D., \& Horgen, K.B. (2003). Food fight: The inside story of the food industry, America's obesity crisis, and what we can do about it. New York: McGraw-Hill.

Burgard (2009). What is "health at every size"? In E. Rothblum \& S. Solvary (Eds.), The fat studies reader (pp. 41-53). New York: New York University Press.

Burrows, L. (2009). Pedagogizing families through obesity discourse. In J. Wright \& V. Harwood (Eds.), Biopolitics and the "Obesity Epidemic": Governing Bodies (pp. 127-140). New York: Routledge.

Butler, J. (1993). Bodies that matter: On the discursive limits of sex. New York: Routledge.

Campo, S., \& Mastin, T. (2007). Placing the burden on the individual: Overweight and obesity in African American and mainstream women's magazines. Health Communication, 22(3), 229-239. doi:10.1080/10410230701626885

Campos, P. (2004). The obesity myth: Why America's obsession with weight is hazardous to your health. New York: Penguin Books.

Campos, P., Saguy, A., Ernsberger, P., Oliver, E., \& Gaesser, G. (2006). The epidemiology of overweight and obesity: Public health crisis or moral panic? International Journal of Epidemiology, 35(1), 55-60. doi:10.1093/ije/dyi254

Catalano, P. (2003). Editorial: Obesity and pregnancy - The propagation of a vicious cycle? The Journal of Clinical Endocrinology and Metabolism, 88(8), 3505-3506. doi:10.1210/ jc.2003-031046

Chou, S.Y., Saffer, H., \& Grossman, M. (2004). An economic analysis of adult obesity: Results from the Behavioral Risk Factor Surveillance System. Journal of Health Economics, 23, 565-587. doi:10.1016/j.jhealeco.2003.10.003

Clarke, A.E., Shim, J.K., Mamo, L., Fosket, J.R., \& Fishman, J.R. (2003). Biomedicalization: Technoscientific transformations of health, illness, and U.S. biomedicine. American Sociological Review, 68(2), 161-194. doi:10.2307/1519765

Clift, K., \& Wright, J. (2010). Confusing and contradictory: Considering obesity discourse and eating disorders as they shape body pedagogies in HPE. Sport Education and Society, 15(2), 221-233. doi:10.1080/13573321003683893

Cohen, L., Perales, D., \& Steadman, C. (2005). The O word: Why the focus on obesity is harmful to community health. Californian Journal of Health Promotion, 3(3), 154-161.

Davies, G., Maxwell, C., \& McLeod, L. (2010). Bulletin number 239: Obesity in pregnancy (SOGC clinical practice guideline). Journal of Obstetrics and Gynaecology Canada, 32(2), 165-173.

Deleuze, G., \& Guattari, F. (1987). A thousand plateaus: Capitalism and schizophrenia. Minnesota: University of Minnesota Press.

Diaz, V.A., Mainous, A.G., \& Everett, C.J. (2005). The association between weight fluctuation and mortality: Results from a population-based cohort study. Journal of Community Health, 30, 153-165. doi:10.1007/s10900-004-1955-1

Ernsberger, (2009). Does social class explain the connection between weight and health? In E. Rothblum \& S. Solvary (Eds.), The fat studies reader (pp. 25-36). New York: New York University Press.

Evans, B. (2006). 'I'd feel ashamed': Girls bodies and sport participation. Gender, Place and Culture: A Journal of Feminist Geography, 13(5), 547-561.

Evans, B., \& Colls, R. (2009). Measuring fatness, governing bodies: The spatialities of the body mass index (BMI) in anti-obesity politics. Antipode, 41(5), 1051-1083. doi:10.1111/j.1467-8330.2009.00706.x

Evans, J., Rich, E., Allwood, R., \& Davies, B. (2005). Fat fabrications. The British Journal of Teaching Physical Education, Winter.

Evans, J., Rich, E., \& Davies, B. (2004). The emperor's new clothes: Fat, thin and overweight. The social fabrication of risk and health. Journal of Teaching in Physical Education, 23(4), 372-392. 
Evans, J., Rich, E., Davies, B., \& Allwood, R. (2008). Education, disordered eating and obesity discourse: Fat fabrications. New York: Routledge.

Farrell, S.W., Braun, L., Barlow, C.E., Cheng, Y.J., \& Blair, S.N. (2002). The relation of body mass index, cardiorespiratory fitness, and all-cause mortality in women. Obesity Research, 10, 417-423. doi:10.1038/oby.2002.58

Farrell, S.W., Finley, C.E., McAuley, P.A., \& Frierson, G.M. (2011). Cardiorespiratory fitness, different measures of adiposity, and total cancer mortality in women. Obesity, 19(11), 2261-2267. doi:10.1038/oby.2010.345

Flegal, K.M. (2010). Prevalence and trends in adult obesity. Journal of the American Medical Association, 303(3), 235-241. doi:10.1001/jama.2009.2014

Flegal, K.M., \& Graubard, B.I. (2009). Estimates of excess deaths associated with body mass index and other anthropometric variables. The American Journal of Clinical Nutrition, 89, 1213-1219. doi:10.3945/ajen.2008.26698

Flegal, K.M., Graubard, B.I., Williamson, D.F., \& Gail, M.H. (2005). Excess deaths associated with underweight, overweight, and obesity. Journal of the American Medical Association, 293(15), 1861-1867. doi:10.1001/jama.293.15.1861

Foucault, M. (1978). The history of sexuality: Vol. I. An introduction. Harmondsworth, England: Penguin Books.

Foucault, M. (1980). Questions of method. In J.D. Faubion (Ed.), Michel Foucault: Power (Vol. 3, pp. 223-238). New York: The New Press.

Foucault, M. (1988). Technologies of the self. In L.H. Martin, H. Gutman, \& P.H. Hutton (Eds.), Technologies of the self: A seminar with Michel Foucault (pp. 16-50). London: Tavistock.

Foucault, M. (1990). (Hurley, R. (trans.)), The history of sexuality: Vol. III. The care of the self. London: Penguin.

Foucault, M. (1994). The birth of the clinic: An archeology of medical perception. New York: Vintage.

Foucault, M. (1995). Discipline and punish: The birth of the prison. New York: Vintage.

Foucault, M. (2008). (Burchell, G. (trans.)) The birth of biopolitics: Lectures at the Collège de France, 1978-1979. New York: Palgrave.

Foucault, M. (2009). (Burchell, G. (trans.)) Security, territory, population: Lectures at the Collège de France 1977-1978. New York: Palgrave.

Garland-Thomson, R. (2005). Feminist disability studies. Signs: Journal of Women in Culture and Society, 30, 1557-1587. doi:10.1086/423352

Gaesser, G.A. (2003a). Pro and con: Is obesity a disease? (No). Family Practice News, 33(16), 12.

Gaesser, G.A. (2003b). "Life lost" to obesity exaggerated. Sports Medicine Digest, 25(4).

Gaesser, G.A. (2003c). Weight, weight loss, and health: A closer look at the evidence. Healthy Weight Journal, 17, 8-11.

Gaesser, G.A. (2006). Study “confirms” you can't be fat and healthy-But what do the data show? Health at Every Size, 20(1), 47-53.

Gaesser, G.A. (2009). Is "permanent weight loss" an oxymoron? The statistics on weight loss and the National Weight Control Registry. In E. Rothblum \& S. Solvary (Eds.), The fat studies reader (pp. 37-40). New York: New York University Press.

Gard, M. (2004). An elephant in the room and a bridge too far, or physical education and the 'obesity epidemic. In J. Evans, B. Davies, \& J. Wright (Eds.), Body knowledge and control. Studies in the sociology of physical education and health (pp. 68-82). London: Routledge.

Gard, M. (2009). Friends, enemies and the cultural politics of critical obesity research. In J. Wright \& V. Harwood (Eds.), Biopolitics and the "Obesity Epidemic": Governing Bodies (pp. 31-44). New York: Routledge.

Gard, M. (2011). The end of the obesity epidemic. New York: Routledge.

Gard, M., \& Wright, J. (2005). The obesity epidemic. Science, morality and ideology. London: Routledge. 
Gelber, R.P., Gaziano, M.J., Oray, E.J., Manson, J.E., Buring, J.E., \& Kurth, T. (2008). Measures of obesity and cardiovascular risk among men and women. Journal of the American College of Cardiology, 52(8), 605-615. doi:10.1016/j.jacc.2008.03.066

Giles, D.C. (2003). Narratives of obesity as presented in the context of a television talk show. Journal of Health Psychology, 8(3), 317-326. doi:10.1177/13591053030083003

Giroux, H.A. (2007). Violence, Katrina, and the biopolitics of disposability. Theory, Culture \& Society, 24(7-8), 305-309. doi:10.1177/02632764070240072510

Goldberg, D. (2009). Disease causality. Literature, Art and Medicine Blog. Available at: http://medhum.med.nyu.edu/blog/?p=211\#comment-2658.

Gregg, E.W., Gerzoff, R.B., Thompson, T.J., \& Williamson, D.F. (2004). Trying to lose weight, losing weight, and 9-year mortality in overweight U.S. adults with diabetes. Diabetes Care, 27, 657-662. doi:10.2337/diacare.27.3.657

Groskopf, B. (2005). The failure of bio-power: Interrogating the 'obesity crisis.' Journal for the Arts. Sciences and Technology, 3(1), 41-47.

Grosz, E. (1994). Volatile bodies: Towards a corporeal feminism. Crows Nest, Australia: Allen and Unwin.

Halse, C. (2009). Bio-citizenship: Virtue discourse and the birth of the bio-citizen. In J. Wright \& V. Harwood (Eds.), Biopolitics and the "obesity epidemic": Governing bodies (pp. 45-59). New York: Routledge.

Hardin, P. (2001). Theory and language: Locating agency between free will and discursive marionettes. Nursing Inquiry, 8, 11-18. doi:10.1046/j.1440-1800.2001.00084.x

Hardt, M., \& Negri, A. (2004). Multitude: War and democracy in the age of empire. New York: Penguin.

Harper, E., \& Rail, G. (2011). "Silhouettes of a pregnant belly": Investigating young pregnant women's discursive constructions of the body. Aporia, 3(1), 6-15.

Harper, E., \& Rail, G. (2012). "Gaining the right amount for my baby": Young pregnant women's discursive constructions of health. Health Sociology Review, 21(1), 69-81.

Harwood, V. (2009). Theorizing biopedagogies. In J. Wright \& V. Harwood (Eds.), Biopolitics and the 'obesity epidemic': Governing bodies (pp. 15-30). London: Routledge.

Herrick, C. (2007). Risky bodies: Public health, social marketing and the governance of obesity. Geoforum, 38(1), 90-102. doi:10.1016/j.geoforum.2006.06.003

Hey, V. (2005). The contrasting social logics of sociality and survival: Cultures of classed be/ longing in late modernity. Sociology, 39(5), 855-872. doi:10.1177/0038038505058369

Himes, S.M., \& Thompson, J.K. (2007). Fat stigmatization in television shows and movies: A content analysis. Obesity (Silver Spring, Md.), 15(3), 712-718. doi:10.1038/ oby. 2007.635

Holm, S. (2007). Obesity interventions and ethics. Obesity Reviews, 8(S1), 207-210. doi:10.1111/j.1467-789X.2007.00343.x

Holmes, B.J. (2009). Media coverage of Canada's obesity epidemic: Illustrating the subtleties of surveillance medicine. Critical Public Health, 19(2), 223-233. doi:10.1080/09581590802478048

Holmes, D., Murray, S.J., Perron, A., \& Rail, G. (2006). Deconstructing the evidence-based discourse in health sciences: Truth, power, and fascism. International Journal of Evidence-Based Healthcare, 4(3), 180-186. doi:10.1111/j.1479-6988.2006.00041.x

Holmes, D., \& O'Byrne, P. (2010). Subjugated to the 'apparatus of capture': Self, sex and public health technologies. Social Theory \& Health, 8(3), 246-258. doi:10.1057/ sth. 2010.7

Inthorn, S., \& Boyce, T. (2010). 'It's disgusting how much salt you eat!' Television discourses of obesity, health and morality. International Journal of Cultural Studies, 13(1), 83-100. doi:10.1177/1367877909348540

IOM (Institute of Medicine) and NRC. (National Research Council) (2009). Weight gain during pregnancy: Reexamining the guidelines. Washington, DC: National Academies Press. 
Jette, S. (2006). "Fit for Two?": A critical discourse analysis of Oxygen fitness magazine. Sociology of Sport Journal, 23(4), 331-351.

Jette, S. (2009). Governing risk, exercising caution: Western medical knowledge, physical activity and pregnancy. Doctoral dissertation, University of British Columbia, Vancouver, B.C.

Jette, S., \& Rail, G. (submitted). Ills from the womb? An examination of pregnancy weight gain advice. Journal of Community Health Nursing.

Kim, S.H., \& Willis, L.A. (2007). Talking about obesity: News framing of who is responsible for causing and fixing the problem. Journal of Health Communication, 12(4), 359-376. doi:10.1080/10810730701326051

Komesaroff, S., \& Thomas, P.A. (2007). Combating the obesity epidemic: Cultural problems demand cultural solutions. Internal Medicine Journal, 37(5), 287. doi:10.1111/j.14455994.2007.01333.x

Kristeva, J. (1982). Powers of horror: An essay on abjection. New York: Columbia University Press.

Lang, T., \& Rayner, G. (2007). Overcoming policy cacophony on obesity: An ecological public health framework for policymakers. Obesity Reviews, 8(s1), 165-181. doi:10.1111/j.1467-789X.2007.00338.x

Lau, D., Douketis, J., Morrison, K., Hramiak, I., Sharma, A., \& Ur, E. (2007). 2006 Canadian clinical practice guidelines on the management and prevention of obesity in adults and children [summary]. Canadian Medical Association Journal, 176(8, Suppl) S1-S13. doi:10.1503/cmaj.061409

LeBesco, K. (2010). Neoliberalism, public health, and the moral perils of fatness. Critical Public Health, First published on 22 December 2010 (iFirst). Available at: http://www. informaworld.com/smpp/section?content=a931520022\&fulltext=713240928.

Lenz, M., Richter, T., \& Mühlhauser, I. (2009). The morbidity and mortality associated with overweight and obesity in adulthood: A systematic review. Deutsches Ärzteblatt International, 106(40), 641-648.

Lloyd-Jones, D., et al. (2009). Heart disease and stroke statistics 2009 update: A report from the American Heart Association Statistics Committee and Stroke Statistics Subcommittee. Circulation, 21-e181 Available at http://circ.ahajournals.org/cgi/content/ full/119/3/e21.

Lyons, P. (2009). Prescription for harm: Diet industry influence, public health policy and the "obesity epidemic". In E. Rothblum \& S. Solvary (Eds.), The fat studies reader (pp. 75-87). New York: New York University Press.

Mark, D. (2005). Deaths attributable to obesity. Journal of the American Medical Association, 293(15), 1918-1919. doi:10.1001/jama.293.15.1918

McDermott, L. (2007). A governmental analysis of children 'at risk' in a world of physical inactivity and obesity epidemics. Sociology of Sport Journal, 24, 302-324.

Miah, A., \& Rich, E. (2006). The medicalisation of cyberspace. London: Routledge.

Miller, P., \& Rose, N. (2008). Governing the present: Administering economic, social and personal life. Cambridge: Polity Press.

Mitchell, R., \& Waldby, C. (2010). National biobanks: Clinical labor, risk production, and the creation of biovalue. Science, Technology \& Human Values, 35(3), 330-355. doi:10.1177/0162243909340267

Monaghan, L.F. (2007). McDonaldizing men's bodies? Slimming, associated (ir)rationalities and resistances. Body \& Society, 13(2), 67-93. doi:10.1177/1357034X07077776

Monaghan, L.F. (2008). Men and the war on obesity: A sociological study. New York: Routledge.

Monaghan, L.F., Hollands, R., \& Pritchard, G. (2010). Obesity epidemic entrepreneurs: Types, practices and interests. Body \& Society, 16(2), 37-71. doi:10.1177/1357034X10364769

Mundy, A. (2001). Dispensing with the truth: The victims, the drug companies, and the dramatic story behind the battle over Fen-Phen. New York: St. Martin's Press. 
Murphy Paul, A. (2008). Too fat and pregnant. The New York Times, Section MM, July 13, p. 19.

Murray, S. (2007). Corporeal knowledges and deviant bodies: Perceiving the fat body. Social Semiotics, 17(3), 361-373. doi:10.1080/10350330701448694

Murray, S. (2008). Pathologizing fatness: Medical authority and popular culture. Sociology of Sport Journal, 25(1), 7-21.

Murray, S.J., Holmes, D., Perron, A., \& Rail, G. (2007). No exit: Intellectual integrity under the regime of 'evidence' and 'best-practices.'. Journal of Evaluation in Clinical Practice, 13, 512-516. doi:10.1111/j.1365-2753.2007.00851.x

Murray, S.J., Holmes, D., \& Rail, G. (2008). On the constitution and status of "evidence" in the health sciences. Journal of Research in Nursing, 13(4), 272-280. doi:10.1177/1744987108093529

National Center for Health Statistics. (2008). Health, United States, 2008 with chartbook. Available at: http://www.cdc.gov/nchs/data/hus/hus08.pdf.

NIH (National Institutes of Health). (1998). Clinical guidelines on the identification, evaluation, and treatment of overweight and obesity in adults (NIH publication no. 98-4083). Bethesda, MD: U.S. Department of Health and Human Services.

Norman, M.E. (2009). Living in the shadow of an obesity epidemic: The discursive construction of boys and their bodies. Doctoral dissertation, University of Toronto, Toronto, Canada.

Novas, C., \& Rose, N.S. (2000). Genetic risk and the birth of the somatic individual. Economy and Society, 29(4), 485-513. doi:10.1080/03085140050174750

O'Byrne, P., \& Holmes, D. (2007). The micro-fascism of Plato's good citizen: Producing (Dis)order through the construction of risk. Nursing Philosophy, 8, 93-102.

Oliver, J.E. (2005). Fat politics: The real story behind America's obesity epidemic. Oxford: Oxford University Press.

Oliver, J.E. (2006). The politics of pathology: How obesity became an epidemic disease. Perspectives in Biology and Medicine, 49(4), 611-627. doi:10.1353/pbm.2006.0062

Onfray, M. (2010). Le crépuscule d'une idole: l'affabulation freudienne. Paris: Grasset et Fasquelle.

Orbach, S. (2006). Commentary: There is a public health crisis-It's not fat on the body but fat in the mind and the fat of profits. International Journal of Epidemiology, 35(1), $67-69 ; 81-82$.

Patton, P. (2005). Capture + politics. In A. Parr (Ed.), The Deleuze dictionary. New York: Columbia University Press.

Puhl, R., \& Brownell, K. (2001). Bias, discrimination and obesity. Obesity Research, 9(12), 788-805. doi:10.1038/oby.2001.108

Rail, G. (2009). Canadian youth's discursive constructions of health in the context of obesity discourse. In J. Wright \& V. Harwood (Eds.), Biopolitics and the "Obesity Epidemic": Governing Bodies (pp. 45-59). New York: Routledge.

Rail, G., \& Lafrance, M. (2009). Confessions of the flesh and biopedagogies: Discursive constructions of obesity on Nip/Tuck. Medical Humanities, 35(2), 76-79. doi:10.1136/ jmh.2009.001610

Rail, G., Holmes, D., \& Murray, S.J. (2010). The politics of evidence on "domestic terrorists": Obesity discourses and their effects. Social Theory \& Health, 8(3), 259-279. doi: $10.1057 /$ sth.2009.10

Rail, G. Murray, S.J., \& Holmes, D. (2010). Human rights and qualitative health inquiry: On biofascism and the importance of parrhesia. In N.K. Denzin \& M.D. Giardina (Eds.), Qualitative inquiry and human rights (pp. 218-242). Walnut Creek, CA: Left Coast Press.

Reece, E.A. (2008). Perspectives on obesity, pregnancy and birth outcomes in the United States: The scope of the problem. American Journal of Obstetrics and Gynecology, 198(1), 23-27. doi:10.1016/j.ajog.2007.06.076 
Rich, E. (2010). Obesity assemblages and surveillance in schools. International Journal of Qualitative Studies in Education, 23(7), 803-821. doi:10.1080/09518398.2010.529474

Rich, E. (2011). 'I see her being obesed!': Public pedagogy, reality media and the obesity crisis. 'Health': An Interdisciplinary Journal for the Social Study of Health. Illness and Medicine, 15(1), 93-121.

Rich, E., \& Evans, J. (2005a). Fat ethics: The obesity discourse and body politics. Social Theory \& Health, 3(4), 341-358. doi:10.1057/palgrave.sth.8700057

Rich, E., \& Evans, J. (2005b). Making sense of eating disorders in schools. Discourse: Studies in the Cultural Politics of Education, 26(2), 247-262. doi:10.1080/01596300500143211

Rich, E., \& Miah, A. (2009). Prosthetic surveillance: The medical governance of healthy bodies in cyberspace. Surveillance \& Society, 6(2), 163-177.

Rich, E., Monaghan, L.F., \& Aphramor, L. (2011). Debating obesity: Critical perspectives. New York: St. Martin's Press.

Ringrose, J., \& Walkerdine, V. (2008). Regulating the abject: The TV make-over as site of neo-liberal reinvention toward bourgeois femininity. Feminist Media Studies, 8(3), 227-246. doi:10.1080/14680770802217279

Robinson, T., Callister, M., \& Jankoski, T. (2008). Portrayal of body weight on children's television sitcoms: A content analysis. Body Image, 5(2), 141-151. doi:10.1016/j. bodyim.2007.11.004

Rose, N. (1999). Powers of freedom: Reframing political thought. Cambridge: Cambridge University Press.

Rose, N. (2006). The politics of life itself: Biomedicine, power, and subjectivity in the twentyfirst century. Princeton, NJ: Princeton University Press.

Ross, B. (2005). Fat or fiction: Weighing the "obesity epidemic." In M. Gard \& J. Wright, The obesity epidemic: Science, morality and ideology (pp. 86-106). London: Routledge.

Roy, S., Faulkner, G., \& Finlay, S. (2007). Fit to print: A natural history of obesity research in the Canadian news media. Canadian Journal of Communication, 32(2/3), 575-594.

Saguy, A.C., \& Almeling, R. (2008). Fat in the fire? Science, the news media, and the 'obesity epidemic.' Sociological Forum, 23(1), 53-83. doi:10.1111/j.1573-7861.2007.00046.x

Saguy, A.C., \& Gruys, K. (2010). Morality and health: News media constructions of overweight and eating disorders. Social Problems, 57(2), 231-250. doi:10.1525/ sp.2010.57.2.231

Skeggs, B. (2005). The making of class and gender through visualizing moral subject formation. Sociology, 39(5), 965-982. doi:10.1177/0038038505058381

Stice, E., Cameron, R., Killen, J.D., Hayword, C., \& Taylor, C.B. (1999). Naturalistic weight reduction efforts prospectively predict growth in relative weight and onset of obesity among female adolescents. Journal of Consulting and Clinical Psychology, 67, 967-974. doi:10.1037/0022-006X.67.6.967

Sunder Rajan, K. (2006). Biocapital: The constitution of postgenomic life. Durham: Duke University Press.

Sykes, H. (2011). Queer bodies: Sexualities, genders, and fatness in physical education. New York: Peter Lang.

Sykes, H., \& McPhail, D. (2011). Fatness: Unbearable lessons. In H. Sykes (Ed.), Queer bodies: Sexualities, genders, and fatness in physical education (pp. 49-74). New York: Peter Lang.

Symonds, M., \& Gardner, D. (2006). The developmental environment and the development of obesity. In P. Gluckman \& M. Hanson (Eds.), Developmental origins of health and disease (pp. 255-264). Cambridge: Cambridge University Press.

Treichler, P. (1999). How to have theory in an epidemic: Cultural chronicles of AIDS. Durham: Duke University Press.

Tumulty, K. (2006) The politics of fat. Time.com. Posted online on 19 March 2006, Available at: http://www.time.com/time/magazine/article/0,9171,1174679,00.html. 
Walkerdine, V., \& Ringrose, J. (2006). Femininities: Reclassifying upward mobility and the neo-liberal subject. In C. Skelton, B. Francis, \& L. Smulyan (Eds.), Gender and education handbook (pp. 31-46). London: Sage.

Warin, M., Turner, K., Moore, V., \& Davies, M. (2008). Bodies, mothers and identities: Re-thinking obesity and the BMI. Sociology of Health \& Illness, 30(1), 97-111. doi:10.1111/j.1467-9566.2007.01029.x

Whitehead, K., \& Kurz, T. (2008). Saints, sinners and standards of femininity: Discursive constructions of anorexia nervosa and obesity in women's magazines. Journal of Gender Studies, 17(4), 345-358. doi:10.1080/09589230802420086

WHO. (World Health Organization) (2000). Obesity: Preventing and managing the global epidemic-WHO Technical Report Series 894. Geneva: World Health Organization. Available: http://www.who.int/nutrition/publications/obesity/WHO_TRS_894/en/ index.html

WHO (World Health Organization). (2011). World Health Organization - Controlling the global obesity epidemic. Available.

http://www.who.int/nutrition/topics/obesity/en/

Wilson, N. (2005). Vilifying former fatties: Media representations of weight loss surgery. Feminist Media Studies, 5(2), 252-255.

Wright, J. (2009). Biopower, biopedagogies and the obesity epidemic. In J. Wright \& V. Harwood (Eds.), Biopolitics and the "Obesity Epidemic": Governing Bodies (pp. 1-14). New York: Routledge.

Wright, J., \& Harwood, V. (Eds.). (2009). Biopolitics and the 'obesity epidemic': Governing bodies. London: Routledge.

Ye, Y., \& Ward, K.E. (2010). The depiction of illness and related matters in two top-ranked primetime network medical dramas in the United States: A content analysis. Journal of Health Communication, 15(5), 555-570. doi:10.1080/10810730.2010.492564 
Copyright of Sociology of Sport Journal is the property of Human Kinetics Publishers, Inc. and its content may not be copied or emailed to multiple sites or posted to a listserv without the copyright holder's express written permission. However, users may print, download, or email articles for individual use. 